\title{
PLASMA CONCENTRATIONS OF EPINEPHRINE AND NOREPI- NEPHRINE DURING INTRAVENOUS INFUSIONS IN MAN *†
}

\author{
BY GERALD COHEN, BERNARD HOLLAND, JOANNE SHA AND \\ MARCEL GOLDENBERG
}

\author{
(From the Departments of Biochemistry, Medicine and Psychiatry, Columbia University College \\ of Physicians and Surgeons; the Nere York State Psychiatric Institute; and the \\ Presbyterian Hospital, New York, N. Y.)
}

(Submitted for publication July 1, 1958; accepted July 9, 1959)

Although numerous clinical studies have centered about the infusion of epinephrine and norepinephrine (1-3), the plasma concentrations attained by the infused catecholamines during such investigations have never been delineated. Recently a highly specific and sensitive procedure for the simultaneous fluorometric determination of epinephrine and norepinephrine in plasma was described $(4,5)$. With this procedure, a detailed investigation of plasma epinephrine and norepinephrine levels during intravenous infusions in man was undertaken and is now documented in the present communication.

\section{EXPERIMENTAL}

Infusion studies were performed on a group of volunteers, viz., medical studients, and on a group of schizophrenic patients at the New York State Psychiatric Institute. Sterile saline solutions of $l$-epinephrine or $l$-norepinephrine (Suprarenin ${ }^{\circledR}$ bitartrate or Levophed(\$) bitartrate monohydrate, Winthrop Stearns Inc., N. Y.) for infusion were prepared at concentrations of 0.5 or $4.0 \mu \mathrm{g}$. free catecholamine per $\mathrm{ml}$. Each study was initiated with a 10 minute control period consisting of a saline infusion, following which the administration of epinephrine or norepinephrine was begun. Infusions were shifted at will from saline to catecholamine by means of a three-way stopcock. Flow rates were controlled by an infusion pump (Process and Instruments Co., New York) which permitted the instantaneous shifting of infusion speeds while the pump was in operation. Flow rates of 1.5 to $7.5 \mathrm{ml}$. per minute were employed.

A total of 41 infusions was performed; these in-

* This research has been supported by Research Grant H-1045 C6 of the United States Public Health Service, National Institutes of Health, Bethesda, Md.; and the Florence L. Pond Gift to the Presbyterian Hospital, N. Y.

$\dagger$ Presented in part before the Division of Pharmacology and Experimental Therapeutics at the Forty-Second Annual Meeting of the Federation of American Societies for Experimental Biology, Philadelphia, Pa., April 14-18, 1958.

$\ddagger$ Deceased July, 1958. cluded 24 infusions with 16 normal subjects ( 15 males and one female) between the ages of 21 and 29 years, and 17 infusions with 14 schizophrenic patients (six males and eight females) between the ages of 18 and 33 years. Subjects received infusions in the left antecubital vein while they were lying on a bed. Blood pressure and pulse were noted at various intervals. Routinely, $30 \mathrm{ml}$. blood specimens were drawn from the right antecubital vein into syringes wetted with heparin solution (sterile Liquaemin Sodium, Organon Inc., Orange, N. J.), and then transferred immediately to cold $40 \mathrm{ml}$. centrifuge tubes equipped with ground glass stoppers. Specimens were chilled in an ice-water bath until the complete set for the particular experiment had been collected. They were then centrifuged at $700 \mathrm{G}$ for 15 minutes following which the supernatant plasmas were removed and analyzed for epinephrine and norepinephrine as described elsewhere $(4,5)$. The plasma concentrations of catecholamine reported in this communication are uncorrected for recoveries which had been demonstrated previously to range from 70 to 90 per cent (5).

Infusions were automatically terminated after infusion speeds of $30 \mu \mathrm{g}$. catecholamine per minute had been reached, or if a pulse pressure of $100 \mathrm{~mm}$. $\mathrm{Hg}$ or a basal pressure increase of $100 \mathrm{~mm}$. $\mathrm{Hg}$ were attained. Cessation of infusions also followed upon request of the subject, report of a persistent headache, or if the subject appeared extremely uncomfortable although willing to continue.

\section{RESULTS}

Constant rate infusions of epinephrine or norepinephrine were characterized by the attainment of steady state plasma concentrations as demonstrated in Figure 1. Although at times fluctuations in the steady state concentrations were observed, particularly for norepinephrine ( $c f$. Curves $B, C$ and $E$ ), the data in general were indicative of the maintenance of a dynamic balance between the rate at which the particular catecholamine was added to plasma and the rate at which it was simultaneously removed. Steady states were maintained for up to 65 minutes, the longest period tested. For epinephrine infusions, steady 

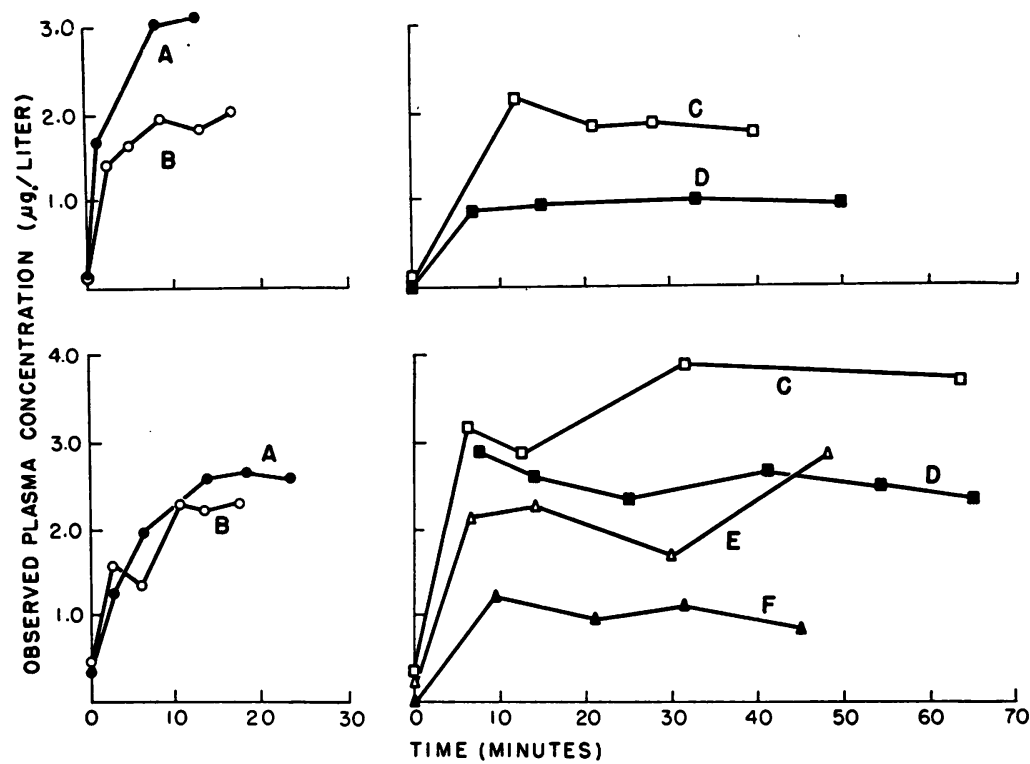

Fig. 1. Peripheral Venous Plasma Concentration of Catecholamine Observed During Constant Rate Intravenous Infusions of EpinephRINE OR NOREPINEPHRINE

Epinephrine infusions (top panel) :

A. Normal female subject, S.D., 22 years, 110 lbs., $21.0 \mu \mathrm{g}$. per minute.

B. Normal male subject, A.K., 21 years, 175 lbs., $21.0 \mu \mathrm{g}$. per minute.

C. Normal male subject, S.T., 24 years, 160 lbs., $20.2 \mu \mathrm{g}$ per minute.

D. Normal male subject, E.B., 23 years, 165 lbs., $12.4 \mu \mathrm{g}$. per minute.

Norepinephrine infusions (bottom panel) :

A. Normal male subject, F.S., 23 years, $150 \mathrm{lbs}$., $21.0 \mu \mathrm{g}$. per minute.

B. Normal male subject, M.N., 22 years, 140 lbs., $17.5 \mu \mathrm{g}$. per minute.

C. Schizophrenic female subject, J.M., 23 years, 120 lbs., $20.0 \mu$ g. per minute.

D. Normal male subject, A.K., 21 years, 175 lbs., $20.8 \mu \mathrm{g}$. per minute.

E. Normal male subject, D.H., 22 years, 140 lbs., $21.0 \mu \mathrm{g}$. per minute.

F. Schizophrenic male subject, R.Z., 18 years, 130 lbs., $11.6 \mu \mathrm{g}$. per minute.

state concentrations were attained within 5 to 10 minutes. For norepinephrine infusions, the time at which the steady state was attained was not always clear due to fluctuations in the observed plasma concentrations; however, roughly 10 minutes or less appeared to have been required.

During the infusion of one catecholamine (either epinephrine or norepinephrine), the changes in plasma concentration of the alternate noninfused catecholamine were small and generally within the limits of accuracy of the analytical procedure. Representative data may be found in Table I where the results of two typical stepwise infusions at successively higher rates are listed. For such infusion studies, blood specimens were drawn at each infusion speed after 10 minutes had elapsed, i.e., at the steady state. Hemodynamic responses to infusions were as previously reported by Goldenberg and co-workers (1). There was considerable variation in intensity of blood pressure and pulse response among the subjects; however, there was no correlation between individual differences in sensitivity and plasma concentrations of the infused pressor amines.

For each individual, the steady state plasma concentration of infused catecholamine was related to the infusion speed in a linear fashion. This is demonstrated in Figure 2 where the results of separate infusions of epinephrine or norepinephrine in the same individual have been graphed. It should be noted that each epinephrine or norepinephrine curve represents a separate infusion of that particular catecholamine. Of particular interest was the finding that for comparable in- 
fusion speeds, norepinephrine attained a higher concentration in plasma than did epinephrine.

The steady state data accumulated during all 41 infusions have been plotted in Figure 3. Very little variation among individuals was evident for steady state concentrations of epinephrine; the data lay on a fairly well defined straight line. For norepinephrine infusions, on the other hand, a much wider range of steady state concentrations was observed; however, it was clear that such variations were not due to any inherent difference between the normal and schizophrenic groups. The highest plasma concentrations attained by the infused catecholamines during these studies were in the neighborhood of $6 \mu \mathrm{g}$. per L. for norepinephrine infusions and $3 \mu \mathrm{g}$. per $\mathrm{L}$. for epinephrine infusions; these values were 10 - to

TABLE I

Blood pressure, pulse and peripheral venous plasma concentrations of epinephrine and norepinephrine during intravenous infusions of either catecholamine (Subject L.M.)*

\begin{tabular}{lllll}
\hline \hline Infusion rate & Time & $\begin{array}{c}\text { Blood } \\
\text { pressure }\end{array}$ & Pulse & $\begin{array}{c}\text { Plasma } \\
\text { concentration }\end{array}$ \\
\hline$\mu g . / \mathrm{Kg} . / \min$. & $\min$. & $\mathrm{mm} . \mathrm{Hg}$ & per min. & $\mu g . / L$.
\end{tabular}

Norepinephrine infusion

\begin{tabular}{|c|c|c|c|c|c|}
\hline $0.000 \dagger$ & $\begin{array}{r}0 \\
8 \\
11\end{array}$ & $110 / 80$ & 68 & 0.16 & 0.02 \\
\hline 0.100 & $\begin{array}{l}15 \\
23 \\
23.5\end{array}$ & $120 / 80$ & 54 & 0.47 & 0.19 \\
\hline 0.203 & $\begin{array}{l}25 \\
35 \\
36\end{array}$ & $140 / 90$ & 48 & 2.14 & 0.23 \\
\hline 0.360 & $\begin{array}{l}37.5 \\
47.5 \\
48\end{array}$ & $160 / 90$ & 52 & 4.43 & 0.36 \\
\hline 0.472 & $\begin{array}{l}58.5 \\
61\end{array}$ & $170 / 90$ & 52 & 6.06 & 0.36 \\
\hline
\end{tabular}

Epinephrine infusion

$\begin{array}{llllll}0.000 \dagger & 0 & & & & \\ & 9 & 110 / 80 & & & \\ 0.094 & 10 & & & & \\ & 12 & & & & \\ & 21 & 140 / 70 & 96 & & \\ 0.188 & 22.5 & & & 0.12 & 0.63 \\ & 25 & & & & \\ 0.313 & 34.5 & 140 / 60 & 108 & & \\ & 35.5 & & & 0.07 & 1.09 \\ & 46 & 140 / 70 & 108 & & \\ & 46.5 & & & 0.03 & 1.90\end{array}$

* Schizophrenic female, 30 years, 140 lbs. $\uparrow$ Saline infusion.

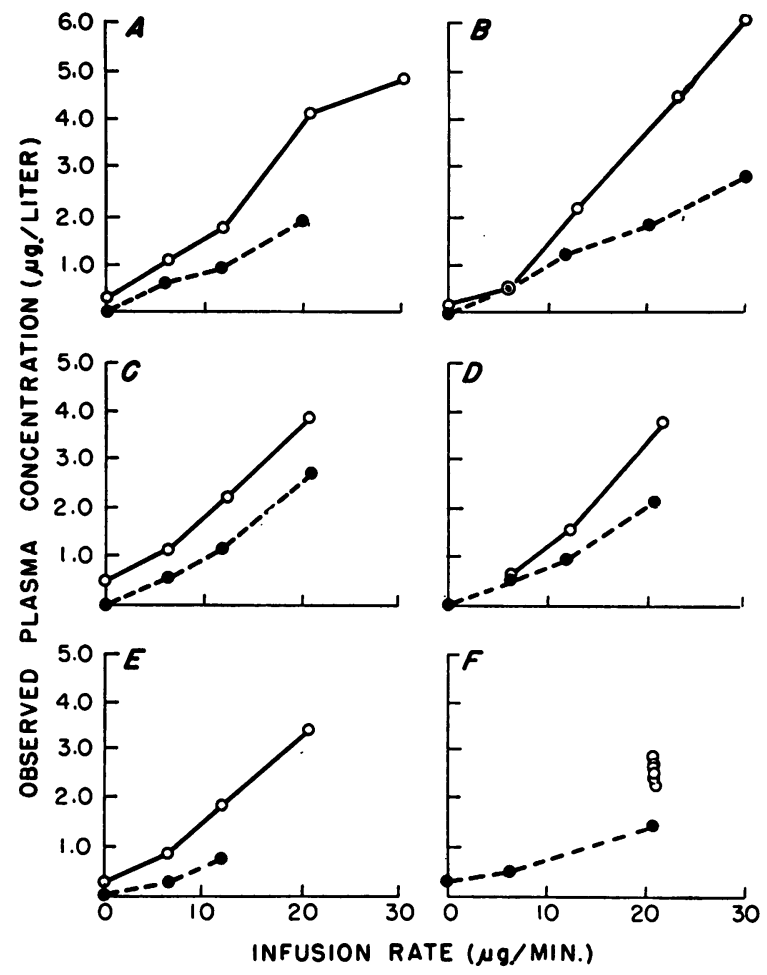

Fig. 2. Comparison of Separate Infusions of EpiNEPHRINe or NoRepinephrine in Several Subjects

Plasma concentrations were measured for each infusion speed after 10 minutes had elapsed, i.e., at the steady state. The concentration of only the infused catecholamine was plotted. Epinephrine is represented by the dashed lines with solid circles; norepinephrine by the solid lines with open circles.

A. Schizophrenic male subject, J.T., 33 years, $155 \mathrm{lbs}$.

B. Schizophrenic female subject, L. M., 30 years, 140 lbs.

C. Normal male subject, A.F., 21 years, 185 lbs.

D. Normal male subject, R.D., 23 years, 140 lbs.

E. Normal male subject, D.P., 22 years, $150 \mathrm{lbs}$.

F. Normal male subject, A.K., 21 years, 175 lbs. The norepinephrine data for this subject were obtained during a prolonged constant rate infusion.

15-fold higher than the highest normal resting values observed, viz., $0.6 \mu \mathrm{g}$. per $\mathrm{L}$. for norepinephrine and $0.2 \mu \mathrm{g}$. per L. for epinephrine.

In several studies, blood specimens were drawn at various time intervals after cessation of the infusion in order to determine the rate of decay of infused catecholamine from plasma. The data obtained are listed in Table II. The decay from plasma was very rapid with a half-life of roughly one to two minutes (cf., Subjects 2, 3, 4 and 6). 


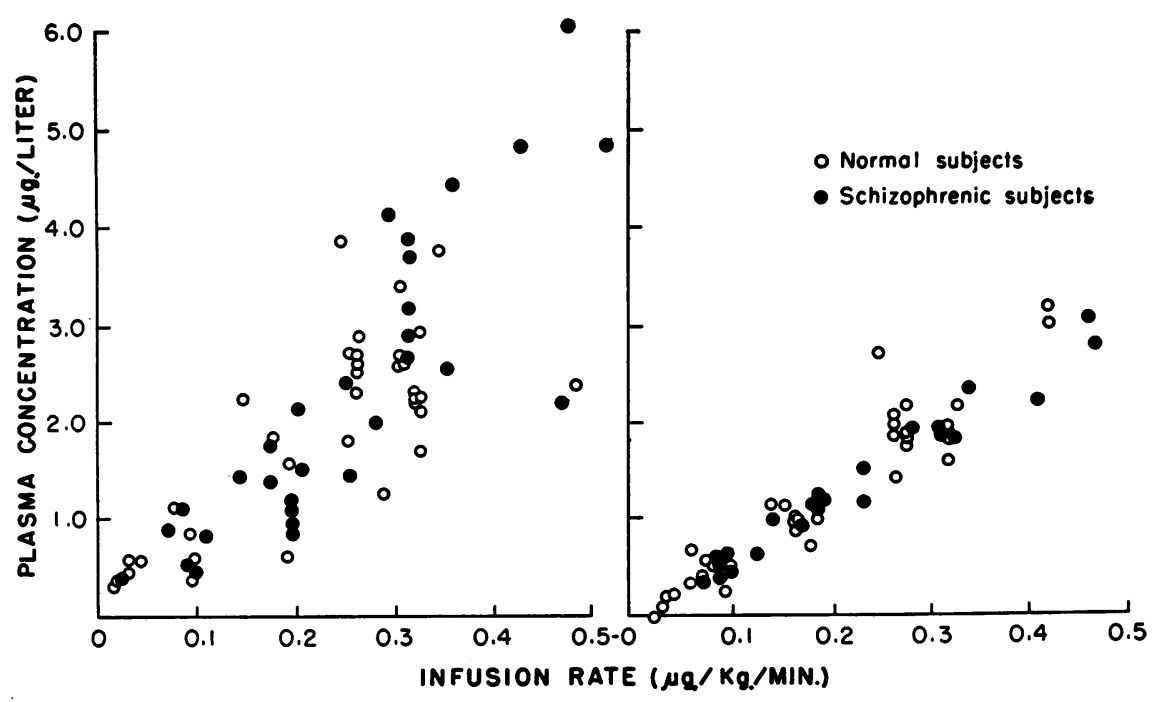

Fig. 3. Steady State Peripheral Venous Plasma Concentrations of Catecholamine Observed During Constant Rate Intravenous Infusions of EpiNEPHRINE (RIGHT) OR NOREPINEPHRINE (LEFT)

Data were obtained during 41 separate infusions of epinephrine or norepinephrine. For each infusion speed, blood specimens were drawn after 10 minutes had elapsed, i.e., at the steady state. In each instance, the plasma concentration of only the infused catecholamine was plotted.

Norepinephrine plasma levels returned to normal within four to eight minutes ( $c f .$, Subjects 4, 5 and 7 ). In a single instance, viz., Subject 1 , there appeared to be a mild elevation in the epinephrine level 10 minutes after cessation of the infusion.

\section{TABLE II}

In vivo rate of decay of infused catecholamines from plasma

\begin{tabular}{|c|c|c|c|}
\hline Subject & $\begin{array}{c}\text { Infused } \\
\text { catecholamine }\end{array}$ & $\begin{array}{l}\text { Sampling time after } \\
\text { infusion halted }\end{array}$ & $\begin{array}{l}\text { Catecholamine } \\
\text { concentration } \\
\text { in plasma }\end{array}$ \\
\hline & & $\min .:$ sec. & $\mu g . / L$. \\
\hline 1 & Epinephrine & $\begin{aligned} 0 & : 00^{*} \\
10 & : 00^{-11}: 00\end{aligned}$ & $\begin{array}{l}2.79 \\
0.39\end{array}$ \\
\hline 2 & Epinephrine & $\begin{array}{l}0: 00^{*} \\
1: 00-1: 40\end{array}$ & $\begin{array}{l}2.70 \\
1.62\end{array}$ \\
\hline 3 & Epinephrine & $\begin{array}{l}0: 00^{*} \\
1: 00-1.50\end{array}$ & $\begin{array}{l}0.71 \\
0.47\end{array}$ \\
\hline & Norepinephrine & $0: 00^{*}-1.50$ & $\begin{array}{l}3.41 \\
3.42 \\
2.50\end{array}$ \\
\hline 4 & Norepinephrine & $\begin{array}{l}0: 00^{*} \\
1: 30-3: 00 \\
7: 00-8: 00\end{array}$ & $\begin{array}{l}2.68 \\
0.72 \\
0.28\end{array}$ \\
\hline 5 & Norepinephrine & $\begin{array}{l}0: 00^{*} \\
4: 00-5: 30\end{array}$ & $\begin{array}{l}0.20 \\
2.43 \\
0.49\end{array}$ \\
\hline 6 & Norepinephrine & $\begin{array}{l}0: 00^{*} \\
0: 30-1: 30\end{array}$ & $\begin{array}{l}1.47 \\
1.25\end{array}$ \\
\hline 7 & Norepinephrine & $\begin{array}{l}0: 00^{*} \\
4: 00-5: 30\end{array}$ & $\begin{array}{l}0.86 \\
0.25\end{array}$ \\
\hline
\end{tabular}

* Sample drawn at steady state, just previous to cessation of infusion.

\section{DISCUSSION}

During a constant rate infusion, the steady state represented a condition in which the rate of addition of catecholamine to plasma was exactly equal to the summation of the rates of the various processes regulating the disappearance of that catecholamine from plasma (viz., diffusion, excretion, metabolic transformation, binding to various tissues and so forth). Although the major source of the elevated plasma catecholamine levels was obviously the infused material, consideration was also given to the possibility of increased endogenous contributions from the body stores such as the adrenal glands and sympathetic nerves. However, the data indicated a lack of significant contributions from these sources. For instance, during norepinephrine infusions the changes in plasma concentration of epinephrine were small (Table I) indicating no major adrenal participation. Similarly, no norepinephrine influx could be detected during epinephrine infusions.

The removal of catecholamine from plasma during infusions was associated with overall first order kinetics as demonstrated by the linearity between steady state concentration and infusion rate (Figure 2). No saturation of the mechanisms 
controlling catecholamine removal from plasma was detected for plasma levels as high as $6 \mu \mathrm{g}$. norepinephrine per L. or $3 \mu \mathrm{g}$. epinephrine per L., i.e., linearity was maintained at these levels. The remarkable degree to which all subjects exhibited similar abilities to remove epinephrine from plasma during infusions was demonstrated by the narrow limits between which the data fell in Figure 3. The wider scattering of the norepinephrine data was no doubt due, at least in part, to the fluctuations in steady state concentrations which were observed at times during constant rate infusions, and also perhaps to individual differences among the subjects. The lack of any difference between data obtained from normal and schizophrenic subjects (Figure 3 ), and the relevance of this observation to current suggestions of defects in epinephrine metabolism associated with schizophrenia, are discussed in greater detail elsewhere (6).

The relatively higher concentrations attained by norepinephrine than by epinephrine during infusions at equivalent rates (Figure 2) indicated that epinephrine was removed from circulation at a faster rate than norepinephrine. However, it should be noted that the strong hemodynamic effects of infusions of epinephrine or norepinephrine may have affected the steady state concentrations. For instance, epinephrine infusions are known to increase blood flow through liver whereas norepinephrine infusions do not (3). Since the liver has been demonstrated to be a major site for epinephrine and norepinephrine inactivation (7), it follows that increased liver blood flow associated with infusions of epinephrine may have resulted in lower steady state concentrations. Other hemodynamic factors such as the increased cardiac output and decreased total peripheral resistance associated with infusions of epinephrine, and the increased total peripheral resistance associated with infusions of norepinephrine (1) may also have been contributory.

\section{Estimation of resting secretion rates}

It may be observed in Figure 3 that average steady state plasma concentrations of roughly 3.5 $\mu$ g. norepinephrine per L. or $2.5 \mu \mathrm{g}$. epinephrine per L. were associated with infusion rates of 0.4 $\mu g$. per $\mathrm{Kg}$. per minute. In the absence of in- fusion of exogenous catecholamine, average normal concentrations (antecubital vein) had been reported previously (5) as $0.30 \mu \mathrm{g}$. norepinephrine and $0.06 \mu \mathrm{g}$. epinephrine per L. plasma. From the linear relationship between infusion rates and steady state concentrations, and from the assumption that resting values were observed under steady state conditions, estimates of the average rates at which endogenous material reach the circulating plasma under resting conditions were calculated as follows :

Norepinephrine, $0.35 \mu \mathrm{g}$. per L.

$$
\begin{aligned}
& \times \frac{0.4 \mu \mathrm{g} \text {. per } \mathrm{Kg} \text {. per min. }}{3.5 \mu \mathrm{g} \text {. per L. }} \\
& \quad=0.04 \mu \mathrm{g} \text {. per } \mathrm{Kg} \text {. per min. }
\end{aligned}
$$

Epinephrine, $0.06 \mu \mathrm{g}$. per L.

$$
\begin{aligned}
& \times \frac{0.4 \mu \mathrm{g} \text {. per } \mathrm{Kg} \cdot \text { per min. }}{2.5 \mu \mathrm{g} . \text { per L. }} \\
& =0.01 \mu \mathrm{g} \text {. per } \mathrm{Kg} \text {. per min. }
\end{aligned}
$$

It should be noted however, that the major portion of endogenous norepinephrine is produced by sympathetic nerves $(8,9)$ which do not secrete directly into the general circulation; hence, only that portion escaping metabolic destruction or binding between the sites of secretion and subsequent entry into the blood circulatory system is reflected in the plasma concentration. Therefore the average endogenous -self-infusion rate calculated for norepinephrine should be distinguished from the average endogenous secretion rate, for which the self-infusion rate represents a lower limit. In comparison, the major portion of endogenous epinephrine enters the circulation directly via the adrenal veins, and hence the endogenous secretion rate for epinephrine may be calculated directly as shown.

\begin{tabular}{|c|c|c|c|}
\hline \multirow[b]{2}{*}{ Patient } & \multicolumn{2}{|c|}{ Plasma concentration } & \multirow[b]{2}{*}{ Calculated secretion rate } \\
\hline & Norepin. & Epin. & \\
\hline $\begin{array}{l}\text { J.T. } \\
\text { K.H. } \\
\text { S.G. } \\
\text { P.L. } \\
\text { J.B. }\end{array}$ & $\begin{array}{l}1.9 \\
3.2 \\
5.6 \\
12.2 \\
30.5\end{array}$ & $\begin{array}{l}0.17 \\
0.14 \\
0.0 \\
0.4 \\
0.2\end{array}$ & 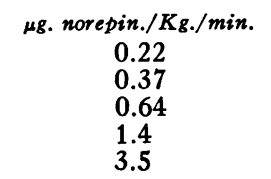 \\
\hline
\end{tabular}

TABLE III

Calculated secretion rates of chromaffin tumors (pheochromocytoma) 
The infusion experiments simulated very closely the situation in patients with norepinephrine and/ or epinephrine producing tumors, i.e., pheochromocytomas. Secretion rates of such tumors could therefore be calculated in the same manner as outlined for resting secretion rates. Several examples of the plasma concentrations observed by us in patients with pheochromocytomas and of the secretion rates to which they corresponded are listed in Table III.

\section{Calculation of turnover times}

The "turnover time" of a hormone has been defined (10) as the time required for complete replacement of circulating hormone by a fresh endogenous supply. At the steady state, the turnover time is given by the equation $T=c v / r$, where $c$ is the average concentration of hormone in plasma, $v$ is the total volume of plasma, and $r$ is the average rate at which hormone is added to blood. For plasma epinephrine and norepinephrine (antecubital vein), a turnover time of 30 seconds was calculated from average steady state concentrations (v) of $3 \mu \mathrm{g}$. per L. associated with infusion rates (r) of $20 \mu \mathrm{g}$. per minute (Figure 2 ), and from an average plasma volume ( $v$ ) of $3.3 \mathrm{~L}$. (based on an average blood volume of $6 \mathrm{~L}$. and an average plasma composition of 55 per cent). Actually the value for epinephrine should be some 20 per cent lower while that for norepinephrine should be some 20 per cent higher than the calculated value on the basis of the relatively lower or higher steady state concentrations observed for each substance, respectively. In comparison the following turnover values in whole blood have been calculated by Pearlman (10) : 3.3 minutes for progesterone, 6 minutes for total estrogens, and 17 minutes for 17-hydroxycorticoids. It should be noted that the turnover time calculated for the infused catecholamines must be the same as that for endogenous secreted pressor amine in view of the linear relationship between infusion rate and steady state concentration (Figures 2 and 3 ).

\section{SUMMARY}

1. Peripheral venous plasma concentrations of epinephrine and norepinephrine were measured during intravenous infusions of these substances.
During infusions, concentrations as high as $3 \mu \mathrm{g}$. epinephrine or $6 \mu \mathrm{g}$. norepinephrine per L. plasma were attained.

2. Constant rate infusions were characterized by the attainment of steady state plasma concentrations within 5 to 10 minutes. Steady state concentrations were directly proportional to infusion speeds. Higher concentrations were attained by norepinephrine than by epinephrine for infusions at comparable speeds.

3. There was very little variation among individuals (both normal and schizophrenic) with regard to rates at which epinephrine was removed from plasma during infusions. Wider variations were noted for norepinephrine.

4. The half-life in plasma of the infused catecholamines was about one to two minutes.

5. Normal endogenous self-infusion rates of $0.04 \mu \mathrm{g}$. norepinephrine per $\mathrm{Kg}$. per minute, and $0.01 \mu \mathrm{g}$. epinephrine per $\mathrm{Kg}$. per minute were calculated from the data. Similar calculations were employed to determine the secretion rates in patients with pheochromocytoma.

6. Turnover times of 30 seconds were calculated for plasma epinephrine and norepinephrine.

\section{ACKNOWLEDGMENT}

The authors are indebted to Dr. Leon Lefer of the New York State Psychiatric Institute for his cooperation in conducting some of the experiments. Grateful acknowledgment is also made of the technical assistance of Mrs. Andre Schwob, Mrs. Patricia Doolin and Mr. Oscar Bing.

\section{REFERENCES}

1. Goldenberg, M., Pines, K. L., Baldwin, E. deF., Greene, D. G., and Roh, C. E. The hemodynamic response of man to norepinephrine and epinephrine and its relation to the problem of hypertension. Amer. J. Med. 1948, 5, 792.

2. Barcroft, H., and Swan, H. J. C. Sympathetic Control of Human Blood Vessels. London, Edward Arnold \& Co., 1953.

3. Bearn, A. G., Billing, B., and Sherlock, S. The effect of adrenaline and noradrenaline on hepatic blood flow and splanchnic carbohydrate metabolism in man. J. Physiol. (Lond.) 1951, 115, 430.

4. Cohen, G., and Goldenberg, M. The simultaneous fluorometric determination of adrenaline and noradrenaline in plasma. I. The fluorescence characteristics of adrenolutine and noradrenolutine and their simultaneous determination in mixtures. J. Neurochem. 1957, 2, 58. 
5. Cohen, G., and Goldenberg, M. The simultaneous fluorometric determination of adrenaline and noradrenaline in plasma. II. Peripheral venous plasma concentrations in normal subjects and in patients with pheochromocytoma. J. Neurochem. 1957, 2, 71.

6. Cohen, G., Holland, B., and Goldenberg, M. Disappearance rates of infused epinephrine and norepinephrine from plasma. A comparison of normal and schizophrenic subjects. A. M. A. Arch. gen. Psychiat. 1959, 1, 228.

7. Lund, A. Elimination of adrenaline and noradrenaline from the organism. Acta pharmacol. (Kbh.) 1951, 7, 297.
8. Goldenberg, M., and Rapport, M. M. Nor-epinephrine and epinephrine in human urine (Addison's disease, essential hypertension, pheochromocytoma) (abstract). J. clin. Invest. 1951, 30, 641.

9. von Euler, U. S., Franksson, C., and Hellström, J. Adrenaline and noradrenaline output in urine after unilateral and bilateral adrenalectomy in man. Acta physiol. scand. 1954, 31, 1.

10. Pearlman, W. H. Circulating steroid hormone levels: in relation to steroid hormone production in $\mathrm{Ciba}$ Foundation Colloquia on Endocrinology, G. E. W. Wolstenholme and E. C. Millar, Eds. Boston, Little, Brown and Co., 1957, vol. XI, p. 233. 